\title{
Proposta de Linha de Cuidado para a Meningococcemia: Detalhando o modelo
}

\author{
Proposal of a Care Line for Meningococcemia: Detailing the model \\ Propuesta de Línea de Atención a la Meningococecemia: Detalle del modelo
}

Recebido: 25/01/2022 | Revisado: 29/01/2022 | Aceito: 30/01/2022 | Publicado: 01/02/2022

Fernando Antônio Ramos Schramm Neto ORCID: https://orcid.org/0000-0002-1375-7315 Universidade Salvador, Brasil

E-mail: fernando78541@ hotmail.com

Carolina Dourado de Faria

ORCID: https://orcid.org/0000-0002-9881-0428

Universidade Salvador, Brasil

E-mail: carolinain11@gmail.com

Alberto Araújo Gordiano Filho

ORCID: https://orcid.org/0000-0003-1428-2048 Universidade Salvador, Brasil

E-mail: albertogordiano@hotmail.com

Anna Luyse Cerqueira Barbosa ORCID: https://orcid.org/0000-0003-3946-784X Universidade Salvador, Brasil

E-mail: annaluyse1020@gmail.com

Camila Rodrigues Blumetti

ORCID: https://orcid.org/0000-0003-2488-8385

Universidade Salvador, Brasil

E-mail: crblumetti@gmail.com

Hellen Moraes Caldas Coqueijo Fidalgo ORCID: https://orcid.org/0000-0003-1429-6730 Universidade Salvador, Brasil

E-mail: hellenfidalgo@gmail.com

Isadora Rodrigues da Costa Barros ORCID: https://orcid.org/0000-0001-9089-7330 Universidade Salvador, Brasil

E-mail: isadora-_rodrigues@hotmail.com

Lahyse de Oliveira e Oliveira ORCID: https://orcid.org/0000-0003-0285-5208 Universidade Salvador, Brasil

E-mail: lahyseoliveira@gmail.com

Luana Beatriz Santos Barbosa Lima ORCID: https://orcid.org/0000-0003-2137-8275 Universidade Salvador, Brasil

E-mail: luanabeatrizmd@gmail.com

Maria Clara Bezerra Gonçalves ORCID: https://orcid.org/0000-0003-3331-253X Universidade Salvador, Brasil

E-mail: mclarabezerra26@hotmail.com

Pedro Alves de Andrade

ORCID: https://orcid.org/0000-0002-3396-6974 Universidade Salvador, Brasil

E-mail: pedroalvesdeandrade @gmail.com

Sara Otoni Blanc

ORCID: https://orcid.org/0000-0002-6282-4422 Universidade Salvador, Brasil

E-mail: saraotoni06@gmail.com

Yasmin de Fátima Vilasboas Alcântara

ORCID: https://orcid.org/0000-0002-1940-5660 Universidade Salvador, Brasil

E-mail: yasminvilasboas2014@gmail.com

Alecianne Azevedo Braga

ORCID: https://orcid.org/0000-0002-4794-7117

Serviço de Atendimento Móvel de Urgência, Brasil

E-mail: alecianne.braga@outlook.com

\section{Resumo}

A doença meningocócica constitui-se como uma infecção causada pela bactéria Neisseria meningitidis, e se caracteriza por gerar, dentre outras sintomatologias, mal-estar, calafrios e cefaleia. Dados dos últimos anos 
evidenciam uma queda relativa do número de acometimentos por esta enfermidade no Brasil, contudo, ainda permanece sendo um grave problema de saúde pública para o país. Portanto, o objetivo deste estudo foi propor a criação de uma nova Linha de Cuidado para a meningococcemia, detalhando todo o modelo apresentado, de forma a englobar os principais níveis de atenção à saúde: primária, secundária e terciária. Para isso, foi feita uma revisão, visando analisar as principais características da doença, bem como apresentar seus dados epidemiológicos, associado a um detalhamento dos pontos principais da Linha de Cuidado proposta. Dentre os resultados apresentados, observase um novo método de integrar as redes de atenção à meningococcemia, de forma a garantir um atendimento mais efetivo aos pacientes portadores de tal enfermidade, com a proposta da nova Linha de Cuidado. Por fim, conclui-se que a meningococcemia se trata de uma doença ainda presente de forma significativa em território brasileiro. Portanto, a proposta da Linha de Cuidado possui importância significativa, visto que cumpre função de complementar as medidas terapêuticas já existentes.

Palavras-chave: Meningite; Meningite meningocócica; Atenção à saúde; Serviços de saúde; Medicina.

\begin{abstract}
Meningococcal disease is an infection caused by the bacterium Neisseria meningitidis, and is characterized by generating, among other symptoms, malaise, chills and headache. Data from recent years show a relative decrease in the number of cases of this disease in Brazil, however, this disease still remains a serious public health problem for the country. Therefore, the objective of this study was to propose the creation of a new Line of Care for meningococcemia, detailing the entire model presented, in order to encompass all the main levels of health care: primary, secondary and tertiary. For this, a review was carried out, aiming to analyze the characteristics of the disease, as well as to present its epidemiological data, associated with a detailing of the main points of the proposed Care Line. Among the results presented, there is a new method of integrating the networks of attention to meningococcemia, in order to guarantee a more effective care for patients with this disease, with the proposal of the new Line of Care. Finally, it is concluded that meningococcemia is a disease still present in a significant way in Brazilian territory. Therefore, the proposal of the Care Line is important because it fulfills the function of complementing the existing therapeutic measures.
\end{abstract}

Keywords: Meningitis; Meningococcal; Delivery of health Care; Health services; Medicine.

\title{
Resumen
}

La enfermedad meningocócica es una infección provocada por la bacteria Neisseria meningitidis, y se caracteriza por generar, entre otros síntomas, malestar general, escalofríos y dolor de cabeza. Los datos de los últimos años muestran una disminución relativa en el número de casos de esta enfermedad en Brasil, sin embargo, esta enfermedad sigue siendo un grave problema de salud pública para el país. Por tanto, el objetivo de este estudio fue proponer la creación de una nueva Línea de Atención a la meningococemia, detallando todo el modelo presentado, con el fin de abarcar todos los principales niveles de atención en salud: primario, secundario y terciario. Para eso, fue realizada una revisión, con el objetivo de analizar las principales características de la enfermedad, así como presentar sus datos epidemiológicos, asociados a un detalle de los principales puntos de la Línea de Atención propuesta. Entre los resultados presentados, se encuentra un nuevo método de integración de las redes de atención a la meningococemia, con el fin de garantizar una atención más eficaz a los pacientes con esta enfermedad, con la propuesta de la nueva Línea de Atención. Finalmente, se concluye que la meningococemia es una enfermedad todavía presente de manera significativa en el territorio brasileño, por lo tanto, la propuesta de la Línea de Atención es importante porque cumple la función de complementar las medidas terapéuticas existentes.

Palabras clave: Meningitis; Meningitis meningocócica; Atención a la salud; Servicios de salud; Medicina.

\section{Introdução}

A meningococcemia é uma infecção causada pelo patógeno Neisseria meningitidis, e pode ter consequências clínicas devastadoras, uma vez que pode levar a um choque irreversível, refletindo no óbito em horas (Chachá et al., 2003). A infecção é causa de epidemias em países desenvolvidos e em desenvolvimento, com incidência de 1 a 1.000 casos em 100.000 habitantes (Takada et al., 2016). A N. meningitidis, também chamada de meningococo, é uma bactéria Gram negativa, aeróbia e diplocócica, que foi isolada pela primeira vez em 1887, cerca de 80 anos depois que causou o primeiro quadro clínico, descrito como uma febre cerebral maligna e não contagiosa (Apicella et al., 2020). A partir daí, estudos descobriram que o agente pertencente à família Neisseriaceae tem 13 sorogrupos, que se distinguem pela estrutura dos seus polissacarídeos capsulares. Contudo, apenas 6 podem causar uma doença potencialmente fatal - A, B, C, W135, X e Y (Apicella et al., 2020).

De acordo com dados do Ministério da Saúde, entre 2007 e 2020, foram notificados um total de 393.941 casos suspeitos de meningite, sendo que a causa bacteriana é a segunda mais frequente, com 87.993 casos - aproximadamente 
22,33\% (Brasil, 2021). Apesar da disponibilidade e incentivo à vacinação, a meningite meningocócica representa 26.436 casos, mesmo sendo levada em consideração uma redução do coeficiente de incidência (CI) - de 1,5 de coeficiente médio para 0,4/100.000 habitantes - após a introdução da vacina meningocócica C (conjugada), nesse mesmo período (Brasil, 2021).

A transmissão do patógeno ocorre através da via respiratória, uma vez que as secreções provenientes da região faríngea, quando em contato com outro indivíduo, permitem a entrada do agente etológico no corpo de um novo hospedeiro, provocando a infecção (Teixeira et al., 2018). A maior parte das pessoas expostas ao agente causador da meningococcemia tornam-se portadoras, apesar de não desenvolverem a doença na sua forma invasiva, sendo os assintomáticos os responsáveis pela principal fonte de transmissão (Takada et al., 2016). Além disso, o risco da transmissão doméstica e em creches é maior devido ao maior contato com pessoas infectadas, especialmente na primeira semana seguinte em que se deu esse contato (Apicella et al., 2020). A doença meningocócica acontece após duas semanas de exposição, sendo que cerca de $20 \%$ dos casos apresentam uma clínica de sepse, o que caracteriza a meningococcemia com disseminação hematogênica, e o restante apresenta um quadro de meningite clássico (Apicella et al., 2020). Assim, uma vez que o patógeno invade a corrente sanguínea podem ocorrer manifestações que variam desde uma bacteremia transitória até a sepse (Takada et al., 2016).

A meningococcemia aguda é comumente antecedida por uma infecção do trato respiratório superior, com sintomas de febre, mal-estar, calafrio, náuseas, vômitos e cefaleia (Takada et al., 2016). Além disso, em seu curso, a doença pode provocar um quadro de hipotensão, coagulação intravascular disseminada, sinais de inflamação meníngea, falência de múltiplos órgãos e manifestação cutânea em forma de petéquias, púrpuras e lesões maculopapulares que, apesar de acometer todo o corpo, incluindo mucosas, tem uma maior predominância nas extremidades (Salzman et al., 1996; Takada et al., 2016).

Apesar dos esforços desprendidos por parte do Ministério da Saúde em ampliar a vacinação no território nacional como forma de combate da Meningococcemia, o país ainda possui um longo percurso para alcançar o seu extermínio (Brasil, 2021). Dessa forma, para melhor atender as necessidades de saúde populacional, é preciso garantir um efetivo fluxo de assistência, apoiado na implementação de protocolos e diretrizes clínicas na forma de linha de cuidado. Para que os indivíduos sejam vistos em sua singularidade como indicadores de saúde e garantam acesso aos serviços e ao cuidado integral, é preciso que haja ações que perpassem desde a prevenção, a detecção precoce e o tratamento. Para isso, todas essas estraté gias precisam adentrar os níveis de atenção com sua devida organização e articulação, sendo as linhas de cuidado as responsáveis por direcionar tais ações de controle, no intuito de reduzir a incidência e a morbidade, ao utilizar os recursos disponíveis da melhor forma.

Portanto, o objetivo geral deste trabalho é promover, através da proposta de criação de uma linha de cuidado, assistência integral à saúde da comunidade, desde a prevenção até o tratamento da meningococcemia. Como objetivos específicos, estão estabelecer protocolos de conduta na identificação precoce da meningococcemia, para reduzir a taxa de morbimortalidade associada, compreender os níveis de atenção básica voltados ao atendimento de pacientes com meningococcemia, e entender a função dos equipamentos de saúde no diagnóstico e tratamento da meningococcemia.

\section{Metodologia}

O presente estudo constitui um artigo original que propõe uma Linha de Cuidado para a meningococcemia, englobando os principais níveis de atenção da saúde pública brasileira: primária, secundária e terciária. Os dados para revisão foram obtidos por meio de levantamento bibliográfico entre setembro e dezembro de 2021, com a revisão em si sendo conduzida durante o mesmo período referido. Como critério de inclusão, fez-se seleção de publicações dos últimos 50 anos, nos idiomas inglês e português. Os descritores em inglês utilizados para o cruzamento foram: "Meningococcemia", "Pathophysiology", "Brazil”. O operador booleano "AND” foi usado para auxiliar nas pesquisas. As bases de dados eletrônicas utilizadas para a pesquisa foram PubMed, SciELO e LILACS, bem como livros publicados sobre o tema. Esta revisão também 
serviu como fonte bibliográfica para a elaboração dos dados e protocolos que compuseram a Linha de Cuidado presente nesse estudo, onde todos os autores buscados na base de dados exerceram suporte teórico adequado e igualitário para o presente estudo. As tabelas 1, 2, 3 e 4 foram elaboradas pelos próprios autores por meio do programa Microsoft Word, com base nos dados epidemiológicos obtidos por meio do Departamento de Informática do Sistema Único de Saúde (DATASUS). Já as figuras 1, 4 e 5 foram elaboradas pelos autores com o auxílio de plataformas específicas, como o Canva. As demais imagens foram adaptadas de fontes bibliográficas encontradas na literatura.

\section{Resultados e Discussão}

\subsection{Situação epidemiológica da Meningococcemia}

\subsubsection{Agente etiológico}

A Neisseria meningitidis (meningococo), é um diplococo gram-negativo, aeróbico, imóvel, envolvido em uma cápsula polissacarídica pertencente à família Neisseriaceae (Takada et al., 2016). Esta bactéria pode causar inflamação nas membranas que revestem o sistema nervoso central (meningite) e infecção generalizada (meningococcemia) (Stella-Silva et al., 2007). A composição antigênica da cápsula polissacarídica permite a classificação do meningococo em 12 diferentes sorogrupos: A, B, C, E, H, I, K, L, W, X, Y e Z. Os sorogrupos A, B, C, Y, W e X são os principais responsáveis pela ocorrência da doença invasiva e, portanto, de epidemias (Castiñeiras et al., 2009). Os meningococos são também classificados em sorotipos e sorossubtipos, de acordo com a composição antigênica das proteínas de membrana externa PorB e PorA, respectivamente (Ministério da Saúde, 2014).

\subsubsection{Modo de Transmissão}

O hospedeiro natural é o homem, sendo a nasofaringe, o local de colonização do microrganismo (Branco et al., 2007). A transmissão se dá pelo contato direto pessoa a pessoa, por meio de secreções respiratórias (gotículas de saliva, espirro, tosse) de pessoas infectadas, assintomáticas ou doentes (Ministério da Saúde, 2014). Após a colonização da nasofaringe, a probabilidade de desenvolver doença meningocócica invasiva dependerá da virulência da cepa, das condições imunitárias do hospedeiro e da capacidade de eliminação do agente da corrente sanguínea (Brasil, 2020). Essa erradicação se dá pela ação de anticorpos séricos com atividade bactericida mediada pela ativação do complemento. O baço também exerce um importante papel na eliminação da bactéria presentes na corrente sanguínea, à medida em que participa do processo de renovação das células sanguíneas inativas, bem como constitui-se num local de depósito de linfócitos B (Branco et al., 2007). As taxas de incidência de portadores são maiores entre adolescentes e adultos jovens e em camadas socioeconômicas menos privilegiadas (Ministério da Saúde, 2014).

\subsubsection{Panorama epidemiológico no Brasil}

Os primeiros casos de meningite no Brasil formam documentados no ano de 1906, e manteve-se endêmica até por volta do ano de 1951 (Paim et al., 2019). A infecção por N. meningitidis tem vasta distribuição pelo território nacional, possuindo também ocorrência anual, e sendo endêmica, com apresentação de casos esporádicos com predomínio no inverno (Goldeman et al., 2009).

Segundo dados do Ministério da Saúde referentes ao ano de 2014, no Brasil, a taxa de letalidade da meningococcemia varia entre 20-50\%, e por ser uma doença de alta letalidade, há necessidade de notificação compulsória (Ministério da Saúde, 2014). A Tabela 1 enumera o total de casos confirmados de meningococcemia, em território brasileiro, entre os anos de 2010 à 2020. 
Tabela 1. Casos confirmados de Meningite meningóccica e meningococcemia entre os anos de 2010-2020, no Brasil

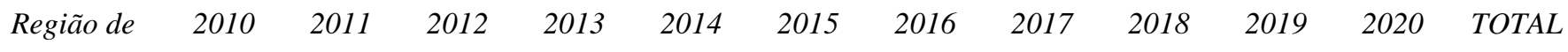

Notificação.

\begin{tabular}{c|cccccccccccc} 
Norte & 36 & 33 & 39 & 37 & 46 & 52 & 42 & 34 & 47 & 33 & 11 & 410 \\
Nordeste & 296 & 298 & 257 & 38 & 117 & 82 & 92 & 67 & 54 & 77 & 25 & 1603 \\
$\begin{array}{c}\text { Sudeste } \\
\text { Sul }\end{array}$ & 1324 & 1217 & 1093 & 865 & 674 & 472 & 396 & 384 & 376 & 37 & 82 & 1720 \\
Centro & 146 & 133 & 94 & 97 & 90 & 106 & 101 & 110 & 118 & 104 & 10 & 1109 \\
Oeste & 86 & 67 & 59 & 53 & 6 & 24 & 24 & 28 & 18 & 24 & 5 & 424 \\
TOTAL & 1888 & 1748 & 1542 & 1290 & 963 & 736 & 55 & 623 & 613 & 575 & 133 & 10766
\end{tabular}

Fonte: Ministério da Saúde/SVS - Sistema de Informação de Agravos de Notificação - Sinan Net.

No panorama nacional, observa-se uma redução da prevalência da doença meningocócica após a introdução da vacina meningocócica conjugada quadrivalente (ACWY). Segundo dados do Ministério da Saúde, o coeficiente médio era de 1,5 caso/100 mil hab. antes da vacinação, período de 2007-2010, passando para 0,4 caso/100 mil hab. no período de 2017- 2020, após a vacinação. Importante salientar que os sorotipos de maior predominância são C e B (Ministério da Saúde, 2014).

\subsubsection{Panorama epidemiológico na Bahia}

Conforme dados do Boletim Epidemiológico das Meningites, Bahia, 2019 - № 1 do ano de 2020, foram confirmados 42 casos de Doença Meningocócica (DM) no ano de 2019, apresentando um coeficiente de incidência (CI) de 0,27 caso/100 mil habitantes. Foram notificados 9 óbitos, com uma letalidade igual a 21,4\% em referência ao ano anterior (Bahia, 2020). Analisando por faixa etária, os grupos de maior risco são menores de 1 ano, de 15 a 19 anos e 30 a 39 anos, como está demonstrado no Gráfico 1.

Gráfico 1. Coeficiente de incidência da doença meningocócica no estado da Bahia, segundo faixa etária, em 2019.

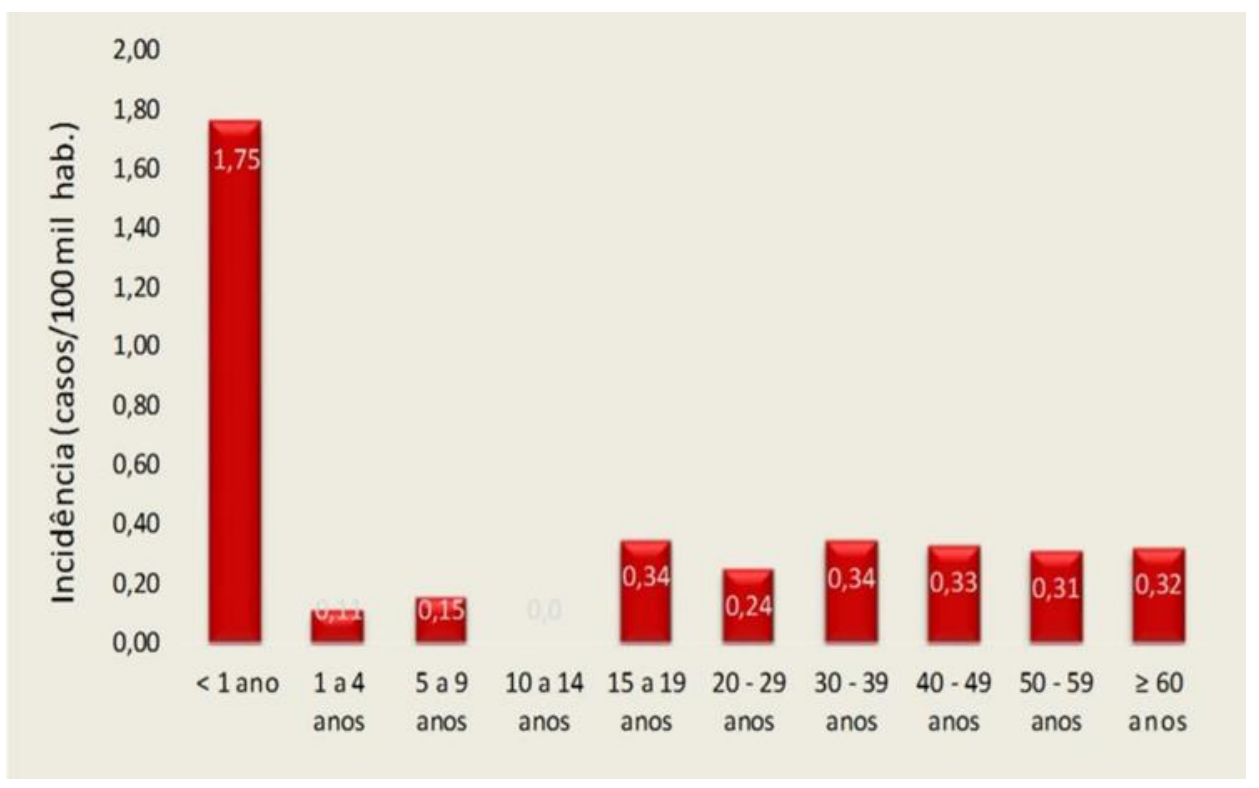

Fonte: Secretaria de Saúde do Estado da Bahia (2020).

De acordo com dados do DataSUS, nos últimos 10 anos é possível se observar uma diminuição do número de casos 
confirmados de meningite meningocóccica+meningococcemia (MM+MCC) e meningococcemia (MCC) no estado da Bahia. Porém, como mostrado na Tabela 2, no ano de 2019 houve um aumento do número de casos nesse estado (Brasil, 2021).

Tabela 2. Casos confirmados de meningite meningocócica + meningococcemia (MM+MCC) e meningococcemia (MCC), entre os anos de 2010-2020, na Bahia.

\begin{tabular}{|c|c|c|c|c|c|c|c|c|c|c|c|c|}
\hline$U \boldsymbol{F}$ & 2010 & 2011 & 2012 & 2013 & 2014 & 2015 & 2016 & 2017 & 2018 & 2019 & 2020 & TOTAL \\
\hline \multicolumn{13}{|l|}{ Notificação } \\
\hline Bahia & 164 & 117 & 75 & 55 & 30 & 18 & 15 & 16 & 5 & 17 & 1 & 513 \\
\hline TOTAL & 164 & 117 & 75 & 55 & 30 & 18 & 15 & 16 & 5 & 17 & 1 & 513 \\
\hline
\end{tabular}

Fonte: Ministério da Saúde/SVS - Sistema de Informação de Agravos de Notificação - Sinan Net.

\subsection{Redes de Atenção à Saúde}

De acordo com o Ministério da Saúde, as Redes de Atenção à Saúde (RAS) se tratam de "arranjos organizativos de ações e serviços de saúde, de diferentes densidades tecnológicas que, integradas por meio de sistemas de apoio técnico, logístico e de gestão, buscam garantir a integralidade do cuidado" (Temporão, 2010). A Portaria nº.279/2010, a qual apresenta diretrizes que instituem as RAS no Sistema Único de Saúde (SUS), estabelece quatro características inerentes a estas redes, sendo elas: (i) formação de relações horizontais entre os diferentes pontos de atenção, tendo a Atenção Primária como o centro coordenador; (ii) oferta de atenção contínua e integral; (iii) atenção multiprofissional; (iv) compartilhamento de objetivos sanitários e econômicos com os resultados (Temporão, 2010).

Uma RAS pode ser estruturada considerando três elementos fundamentais: população; estrutura operacional; e modelo de atenção à saúde (Figura 1). A população de uma área geográfica deve ser estudada com o intuito de elucidar fatores de risco relacionados ao desenvolvimento de determinadas patologias (Temporão, 2010). Para isso, devem ser levados em consideração a territorialização, a vinculação das famílias aos pontos de saúde, a identificação e estratificação de subpopulações de acordo com riscos sociais, sanitários e condições de saúde, dentre outras características (Temporão, 2010). A estrutura operacional é formada pela atenção primária (centro coordenador), secundária e terciária, serviços de apoio (instituições nas quais se realizam serviços comuns a todos os pontos de atenção à saúde), sistema logístico e os sistemas de governança (arranjo organizativo que permite a gestão de todos os componentes das RAS) (Tabela 3) (Oliveira et al., 2015). O modelo de atenção à saúde, por sua vez, é um sistema que organiza o funcionamento destas redes, a partir das condições epidemiológicas e dos determinantes sociais da saúde em uma sociedade específica (Oliveira et al., 2015). 
Figura 1. Estrutura de uma Rede de Atenção à Saúde.

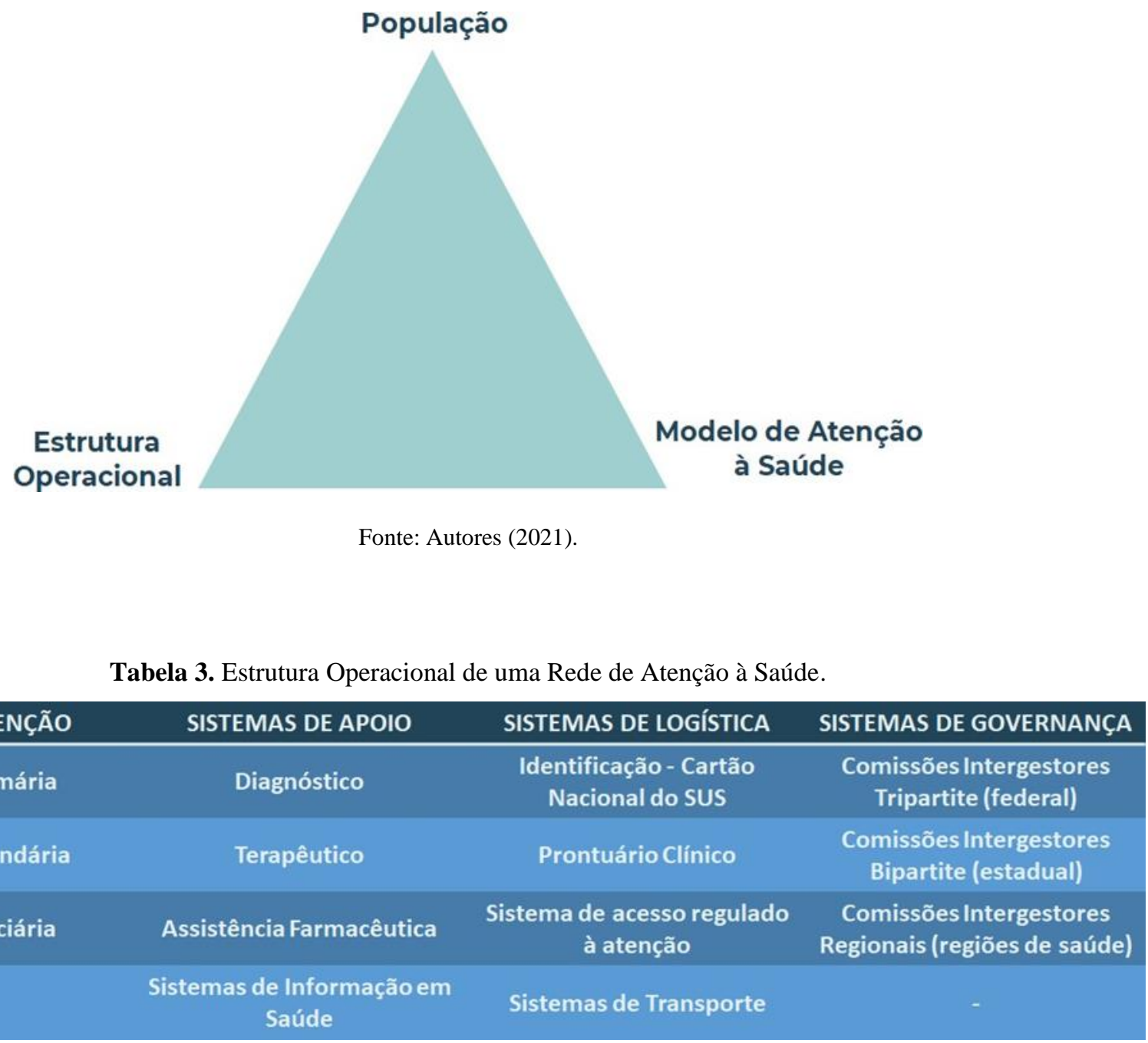

Fonte: Autores (2021).

Existem algumas redes temáticas de atenção à saúde já bem estabelecidas, tais como: rede cegonha; rede de atenção psicossocial; rede de atenção às urgências e emergências; rede de atenção às doenças e condições crônicas; e a rede de cuidado à pessoa com deficiência (Brasil, 2020). No que se refere ao atendimento de casos de meningococcemia, o direcionamento deve ser feito para a rede de atenção às urgências e emergências, visto que se trata de uma emergência neurológica, que se não diagnosticada e tratada precocemente, tem alto risco de levar o paciente a óbito (Noronha et al., 2008). Esta rede "visa articular e integrar todos os equipamentos de saúde para ampliar e qualificar o acesso humanizado e integral aos usuários em situação de urgência/emergência nos serviços de saúde de forma ágil e oportuna”, segundo a Portaria MS/1600 (Temporão, 2010).

Como toda rede, é a atenção básica que ordena todo o cuidado daquele território. Transversalmente, o que difere a rede de urgência das outras é o acolhimento, visto que independente do ponto de atenção que o paciente estiver, ele deve ser acolhido e ter o seu risco classificado (Temporão, 2010). A classificação de risco é uma ferramenta utilizada nos serviços de urgência e emergência, voltada para avaliar e identificar os pacientes que necessitam de atendimento prioritário, de acordo com a gravidade clínica, potencial de risco, agravos à saúde ou grau de sofrimento, e, a partir disso definir o ponto de atenção adequado para aquela situação (Brazil, 1985). A Figura 2 retrata os princípios básicos adotados por cada componente das Redes de Atenção às Urgências e Emergências. 
Figura 2. Componentes da Rede de Atenção às Urgências e Emergências.

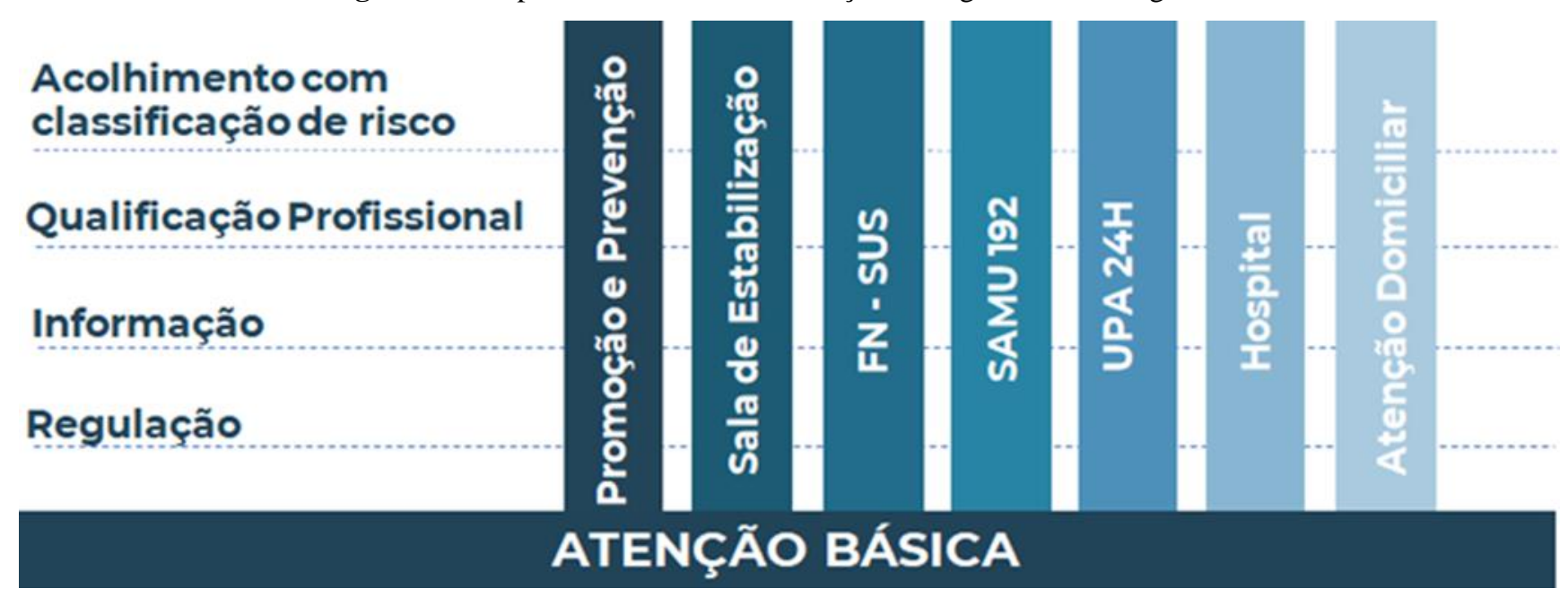

Fonte: Adaptado de SAS/MS (2011).

\subsection{Linha de Cuidado ao paciente com Meningococcemia}

As Linhas de Cuidado constituem-se como modelos de oferta de atenção central, formadas por um conjunto de saberes, tecnologias e recursos necessários ao enfrentamento de determinados riscos, agravos ou condições específicas, sendo voltadas às especificidades de grupos, ou necessidades individuais (Silva et al., 2016). Tais modelos devem ser ofertados de maneira oportuna, articulada e contínua, pelo sistema de saúde, e a sua implementação deve ser estratégia central para o processo organizacional e qualificatório das redes de atenção à saúde, com vistas à integralidade da atenção (Malta et al., 2010). A implementação da Linha de Cuidado tem como centro coordenador as unidades da Atenção Primária à Saúde (APS), e tem como intuito unir as respostas fragmentadas dos pontos de atenção em uma resposta global e integral à saúde (Malta et al., 2010).

Atualmente, não existe uma Portaria que garanta uma Linha de Cuidados específica para a Meningococcemia, tais como os modelos já presentes para o Infarto Agudo do Miocárdio (IAM), ou para Acidente Vascular Encefálico (AVE) (Brasil, 2020). A meningococcemia se trata de uma patologia altamente letal, e, no Brasil, se constitui ainda como uma enfermidade endêmica, se manifestando por meio de surtos em diversos municípios, com um coeficiente de incidência de aproximadamente 1,8 casos para cada 100.000 habitantes, sendo muitos dos casos, ainda subnotificados, o que pode tornar tal taxa ainda maior (Pacheco et al., 2007). Dessa forma, a elaboração de uma linha de cuidado que possibilite o diagnóstico precoce e terapia, se manifesta como um elemento primordial para a consolidação do acolhimento e atendimento oferecido à tal enfermidade, de forma a se tornar dinâmico e abrangente dentro do sistema de saúde brasileiro.

\subsubsection{Níveis de Atenção à Saúde}

O modelo estrutural brasileiro de atenção à saúde segue a classificação da Organização Mundial da Saúde (OMS), o qual estabelece três níveis no atendimento de acordo com a complexidade necessária para cada caso: o primário, o secundário e o terciário (Brasil, 2020). A portaria 4.279 descreve que estes níveis são:

Fundamentais para o uso racional dos recursos (...), estruturam- se por meio de arranjos produtivos conformados segundo as densidades tecnológicas singulares, variando do nível de menor densidade (APS), ao de densidade tecnológica intermediária, (atenção secundária à saúde), até o de maior densidade tecnológica (atenção terciária à saúde) (BRASIL, 2010). 
Os sistemas de saúde secundários e terciários oferecem serviços especializados com média e alta densidades tecnológicas, respectivamente, e servem de apoio à Atenção Básica. Contudo, não devem ser considerados como os pontos de atenção principais, visto que fazem parte de uma rede poliárquica (Oliveira et al., 2016).

\subsubsection{Atenção Primária}

A Atenção Primária à Saúde (APS) é a principal porta de entrada do SUS e o centro coordenador, que permite a comunicação e organização dos fluxos do sistema de atenção à saúde (Mendes, 2008). Este modelo estimula a proximidade com a população assistida em determinado território e garante a integralidade e continuidade da assistência aos usuários. (Mendes, 2015). O primeiro nível de atenção em saúde se caracteriza por ações de saúde desde a promoção e prevenção de doenças, ou seja, é o contato inicial da população para redução de riscos de adquirir determinadas patologias (Mendes, 2015). Para isso, neste âmbito são feitas campanhas de conscientização, vacinação, consultas e exames de baixa complexidade para estimular a manutenção de uma vida saudável (Mendes, 2015).

Dentro da Atenção Primária, os pontos de Atenção da Rede são:

- Unidade Básica de Saúde (UBS): são as portas de entrada preferencial do SUS. Esses postos são responsáveis por até $80 \%$ dos problemas de saúde através do acompanhamento da comunidade e ações de educação em saúde, identifica as necessidades de vida da população, realiza a estratificação de riscos, o tratamento, subsidiando a organização do cuidado em toda a rede (Medeiros, \& Araújo-Souza, 2010).

- Polo da Academia da Saúde: implantação de espaços públicos onde são ofertadas atividades físicas para a população. Esse polo potencializa ações de cuidados individuais e coletivos na atenção primária, culturalmente inserido e adaptado aos territórios, contemplando práticas corporais e atividades físicas; produção do cuidado e de modos de vida saudáveis; práticas integrativas e complementares; práticas artísticas e culturais; educação em saúde; planejamento e gestão; e mobilização da comunidade (Sá et al., 2016).

Estratégias para o apoio matricial e institucional às equipes:

- Núcleo de Ampliado da Saúde da Família (NASF-AB): equipes multiprofissionais que atuam de forma integrada nas equipes de Saúde da Família (eSF), as equipes de atenção básica para populações específicas (consultórios na rua, equipes ribeirinhas e fluviais) e com o programa Academia da saúde. Realiza suporte clínico e pedagógico para qualificação da atenção por meio da educação permanente presencial e à distância, atendimentos individuais e coletivos compartilhados, atendimentos específicos e discussão de casos que necessitem a regulação da RAS, ampliando a oferta de serviços. (Vendruscolo, Ferraz, Tesser, \& Trindade, 2019).

- Apoio institucional da Gestão: acompanha/orienta as equipes de saúde por meio da educação permanente à distância (minicursos, webpalestras e fóruns de discussão) a (re)organização do processo de trabalho da atenção primária para qualificar o acesso à APS no momento mais oportuno (Mendes, 2015).

Para a Meningococcemia, embora não exista um modelo específico de linha de cuidado, algumas medidas de prevenção e promoção estão sendo aplicadas no Brasil. Contudo, algumas outras medidas devem ser aderidas pelo Ministério da Saúde, para que haja o combate efetivo à meningite meningocócica, doença que pode evoluir com meningococcemia. A Tabela 4 faz referência às medidas de prevenção e promoção já existentes, bem como as propostas para o combate à meningococcemia. 
Tabela 4. Medidas existentes e propostas para o combate à meningococcemia.

\section{Medidas Existentes}

Campanhas de Vacinação

Dia Mundial de Combate às Meningites

24 de Abril
Medidas Propostas

Distribuição de panfletos educativos

Divulgação sobre o tema em redes sociais

Vacinação - sorotipos ACWY (SBIm)

Fonte: Autores (2021).

Existem campanhas de vacinação contra o meningococo $\mathrm{C}$ feitas periodicamente para as seguintes faixas etárias: 3 e 5 meses, com um reforço aos 12 meses, que pode ser aplicado até antes de se completar 5 anos; e uma dose para adolescentes com 11 a 12 anos (como reforço ou dose única, a depender da situação vacinal), seguindo o Plano Nacional de Imunização (PNI) (Mendes, 2015). Contudo, ao longo dos últimos anos, o índice de vacinação do público infantil, sobretudo crianças menores de 11 anos, vem diminuindo consideravelmente, em virtude da menor adesão dos pais ou responsáveis dos mesmos, ao programa de vacinação (Mendes, 2015).

Levando isso em consideração, esse estudo propõe a criação de panfletos educativos, para que sejam utilizados como medida educativa na Atenção Primária da Linha de Cuidado da Meningococcemia. Estes panfletos devem ressaltar a importância da vacinação contra a meningite meningocócica, bem como as características da enfermidade. Tais materiais seriam distribuídos de forma virtual e física, em Unidades Básicas de Saúde (UBS), com base num levantamento epidemiológico elaborado por Agentes Comunitários em Saúde (ACS) das regiões com menor adesão vacinal e maior número de notificações. Tais dados seriam utilizados para a melhor distribuição dos panfletos. A Figura 4 retrata o modelo de panfleto proposto pela equipe: 
Research, Society and Development, v. 11, n. 2, e45611226131, 2022

(CC BY 4.0) | ISSN 2525-3409 | DOI: http://dx.doi.org/10.33448/rsd-v11i2.26131

Figura 4. Modelo de panfleto educativo "Vacine seu filho contra a Meningite meningocócica".
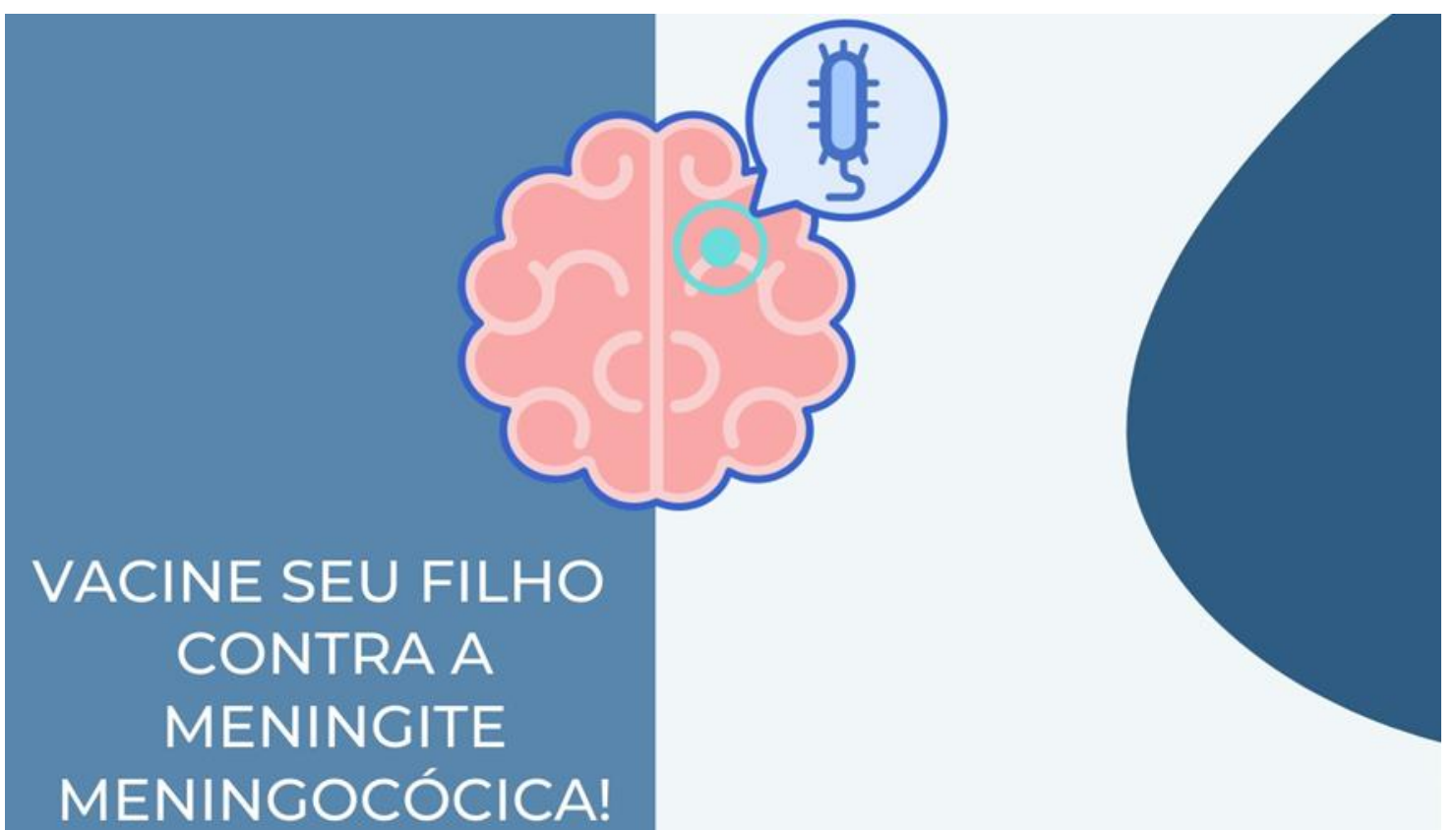

MENINGOCÓCICA! anos, leve na UBS mais próxima para vacinar.
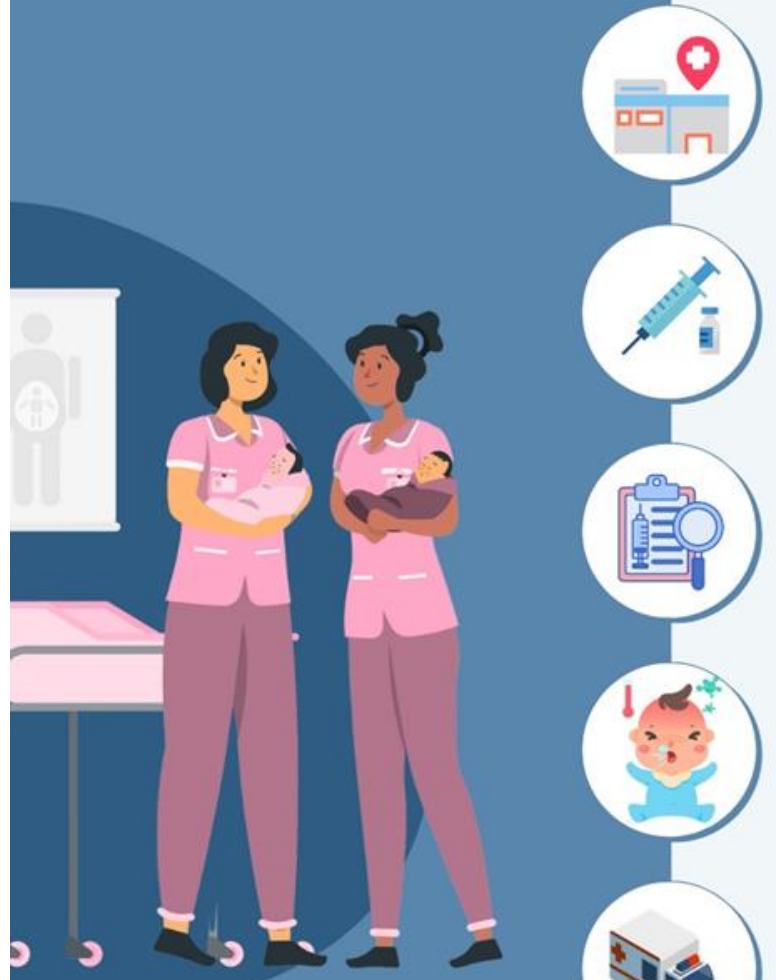

Agende seu horário de vacinação 1 a 2 dias antes.

Lembre-se de seguir as medidas de segurança adequadas no local da vacina.

Atente-se aos sintomas: febre alta, dor de cabeça, alteração de comportamento e rigidez na nuca.

Em caso de sintomas, ligue imediatamente para o SAMU 192.

PARA MAISINFORMAÇÕES ACESSE NOSSAS REDES SOCIAIS @TODOSCONTRAMENINGOCOCCEMIA
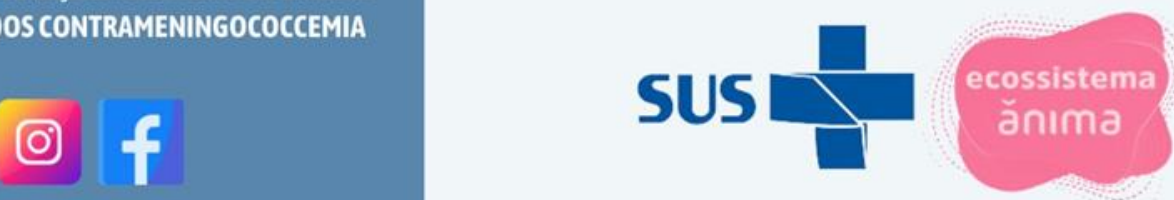

Fonte: Autores (2021). 
Propomos também a antecipação da imunização contra os sorotipos AWY do meningococo no PNI para crianças, além do sorotipo C, como preconizado pela SBIm, assim como dose de reforço para adultos. Além disso, é importante inserir a vacina meningocócica B no calendário vacinal, sendo recomendada para crianças a partir de 3 meses e para adolescentes, pela SBIm (Stella-Silva et al., 2007).

Além disso, existe o Dia Mundial de Combate às Meningites, que ocorre no dia 24 de abril, elaborado pela Confederation of Meningitis Organisations (CoMO), com o objetivo de proporcionar uma maior conscientização à população acerca dos principais aspectos que permeiam tal enfermidade, bem como a importância da prevenção, diagnóstico precoce e medidas de suporte para quem necessita. No entanto, a pouca divulgação realizada pelo Ministério da Saúde (MS), torna tal evento desconhecido pela maioria da população brasileira. Portanto, visando atribuir melhorias na disseminação de informações acerca da Meningite Meningocócica, propõe-se o uso das redes sociais para alcançar maior visibilidade a respeito do tema, bem como uma maior promoção e prevenção relacionada a esta patologia.

\subsubsection{Atenção Secundária}

A Atenção Secundária é responsável pelo atendimento ambulatorial e hospitalar com procedimentos de média complexidade, fornecendo assistência à Atenção Primária (Mendes, 2015). Esse nível compõe-se de serviços médicos especializados, de apoio diagnóstico e terapêutico, e atendimento de urgência e emergência (Erdmann, Andrade, Mello, \& Drago, 2013). As unidades assistenciais são espaços e estruturas da Rede de Atenção à Saúde, como UPAs e SAMU, e seus respectivos recursos de prestação de serviço, equipamentos, materiais e recursos humanos (Erdmann, Andrade, Mello, \& Drago, 2013). Dentre elas, as mais importantes e as suas respectivas funções são:

- Unidade de Pronto Atendimento (UPA): faz parte da Rede de Atenção às Urgências e Emergências. Seu objetivo é concentrar os atendimentos de saúde de complexidade intermediária, evitando a sobrecarga dos prontos socorros dos hospitais. (Briozo, \& Musetti, 2015).

- Hospital Geral: os pontos de atenção hospitalar, junto às UPA e ao Serviço de Atendimento Móvel de Urgência (SAMU). Essa interface de alta complexidade é fundamental no intuito de promover a assistência integral em regime de internação ou de não internação, no caso de ambulatório ou outros serviços. (Brazil, 1985)

- Ambulatórios especializados: conjunto de serviços e ações eletivas de média e de alta, preferencialmente ofertado de forma hierarquizada e regionalizada, para assegurar tanto uma boa relação custo/benefício quanto a qualidade da atenção a ser prestada. (Solla et al., 2008).

- Atendimento Domiciliar: realiza ações de tratamento de doenças e reabilitação visando a diminuição das repercussões negativas da doença, com garantia da continuidade do cuidado a domicílio (Solla et al., 2008).

O acesso a essas unidades acontece através da demanda regulada pelo Sistema de Regulação do SUS (Sisreg), orientando o fluxo de atendimentos ambulatoriais, a livre demanda dos atendimentos de urgências que são classificados por risco, e por transporte de pessoas em situação de risco, caso necessário (Erdmann et al., 2013).

Dentro da estrutura que compõe a atenção secundária, os pacientes portadores de Meningococcemia encontram profissionais de saúde preparados para realizar procedimentos de tratamento de intermediária complexidade. Por conta disso, é possível associar índices positivos de recuperação de enfermos com tal mazela, com o atendimento prestado pela atenção secundária à saúde (Erdmann et al., 2013). Todas as unidades que compõem a atenção secundária de saúde, devem dispor de uma estrutura mínima recomendada para o manejo inicial prestado a pacientes com Meningococcemia (Oliveira et al. 2016). Dentre tais condições, podem ser citados: 
- Isolamento inicial dos pacientes portadores de tal enfermidade, nas salas de isolamento de doenças infectocontagiosas, presentes nas Unidades de Pronto Atendimento (UPAs) até ocorrer a regulação do paciente para um hospital especializado;

- Equipe multidisciplinar especializada na instalação de medidas de suporte e manejo inicial, conforme suspeita clínica;

- Direcionamento rápido para que se garanta a hospitalização necessária ao paciente;

- Notificação do caso à Secretaria Municipal de Saúde e/ou Distrito Sanitário, visando garantir a investigação epidemiológica, além da adoção das medidas de controle;

- Estabilização inicial do quadro clínico do paciente, até o seu direcionamento a um centro de Atenção Terciária;

- Em caso de atendimento inicial do paciente pelo SAMU, haverá o seu direcionamento a um ponto da Atenção Terciária.

\subsubsection{Atenção Terciária}

A Atenção Terciária é um atendimento altamente especializado para pacientes que podem estar internados e precisam de cirurgias e exames mais invasivos, como procedimentos que envolvem alta tecnologia e/ou alto custo, a exemplo oncologia, cardiologia, oftalmologia, transplantes, parto de alto risco, traumato-ortopedia, neurocirurgia, diálise e otologia (Carvalho et al., 2016). Envolve também a assistência em cirurgia reparadora, cirurgia bariátrica, cirurgia reprodutiva, reprodução assistida, genética clínica, terapia nutricional, distrofia muscular progressiva, osteogênese imperfeita e fibrose cística (Carvalho et al., 2016). Entre os procedimentos ambulatoriais de alta complexidade estão a quimioterapia, a radioterapia, a hemoterapia, a ressonância magnética e a medicina nuclear, além do fornecimento de medicamentos excepcionais, tais como próteses ósseas, marca-passos, stent cardíaco etc. (Noronha et al., 2008). Nesse momento, os pacientes podem ter doenças graves que representam risco à sua vida, por isso, eles devem ser encaminhados para as seguintes unidades:

- Hospital com leitos de Unidade de Terapia Intensiva (UTI): destinado ao acolhimento de pacientes em estado grave, prestando suporte e monitoramento constante às funções vitais, durante condições clínicas de gravidade extrema e risco de morte por insuficiência orgânica (Brasil, 2020).

- Hospital e/ou Unidade de Neurologia: assistência especializada ao paciente com doenças neurológicas de alta complexidade.

Pacientes com suspeita de doença meningocócica devem ser encaminhados para um hospital especializado o mais breve possível. Ao chegar na unidade não deve ter o tratamento adiado, visto que a progressão dos sintomas iniciais até a morte pode ocorrer em menos de 24 horas (Castiñeiras et al., 2009). Dessa forma, toda a equipe multiprofissional deve estar preparada para agir de forma protocolada e sistematizada para melhor prognóstico do enfermo. Em casos de meningite meningocócica, em que o paciente ainda não evoluiu para disseminação hematogênica do agente etiológico, normalmente primeiro é feita a coleta do LCR para investigação antes de iniciar o tratamento propriamente dito (Castiñeiras et al., 2009). A equipe deve estar preparada para saber diferenciar a evolução do quadro e saber atuar em cada um deles.

Para melhor desempenho dos profissionais da saúde no atendimento dessa emergência neurológica propomos a aplicação de cursos de treinamentos teórico-práticos periódicos para o manejo destes pacientes, possibilitando o diagnóstico e tratamento cada vez mais precoces, reduzindo a morbimortalidade pela meningococcemia. Cada secretaria de saúde estadual deve selecionar os hospitais que serão considerados os pontos principais de atendimento a pacientes com suspeita de meningite meningocócica ou meningococcemia e executar treinamentos semestrais com a equipe de saúde. Além disso, ao final do curso devem ser elaboradas provas objetivas para avaliar o desempenho e evolução dos profissionais. A Figura 5 sintetiza os 
principais pontos abordados e propostos por este estudo, para cada nível de atenção aos pacientes portadores de meningococcemia:

Figura 5. Fluxograma acerca da Linha de Cuidado contra a meningococcemia.

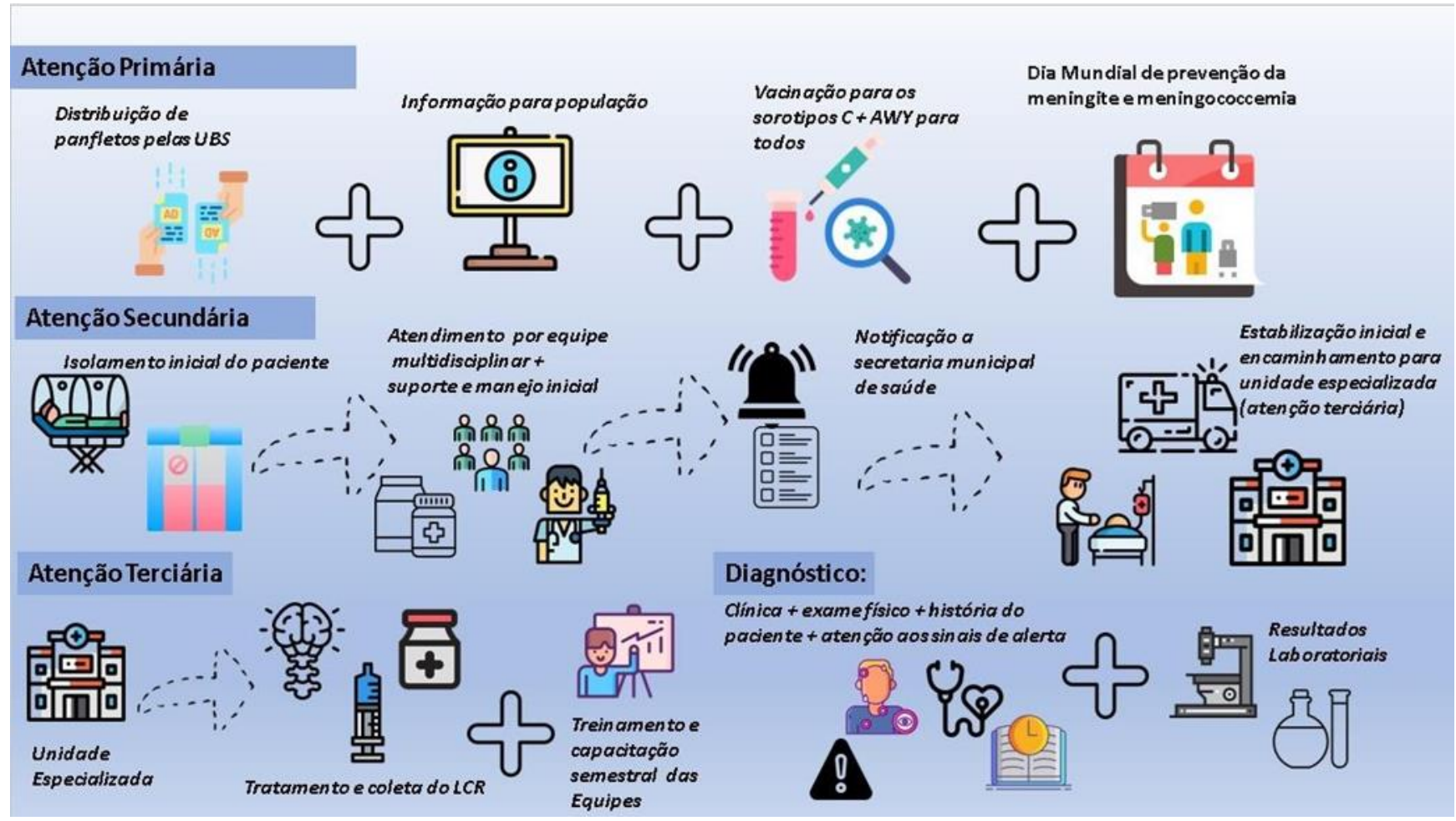

Fonte: Autores (2021).

\subsection{Diagnóstico}

A meningococcemia, síndrome clínica mais grave da doença meningocócica, pode levar o paciente ao óbito em poucas horas, necessitando de um rápido diagnóstico e imediata intervenção (Mendes, 2015). O diagnóstico inicial deve ser baseado na clínica do paciente, associando história, exame físico e excluindo outras possíveis causas. (Bahia, 2019). Durante a avaliação clínica, o médico deve estar atento à não obrigatoriedade de alguns sinais e sintomas na meningococcemia, principalmente quando comparado às outras síndromes da doença meningocócica, como por exemplo a rigidez de nuca, e sempre ter como hipótese diagnóstica a meningococcemia diante da presença de eritema/exantema, além dos sinais e sintomas inespecíficos, sugestivos de septicemia, como hipotensão, diarreia, dor abdominal, dor em membros inferiores, mialgia, rebaixamento do sensório, visto que a maiorias dos óbitos da já elevada taxa de letalidade da patologia ocorre nas primeiras 48 horas do início dos sintomas, sendo caracterizada portanto como uma emergência médica (Bahia, 2019).

Diante de um caso suspeito, é de responsabilidade da unidade de saúde o primeiro atendimento, estabilizando, hidratando, além de iniciar imediatamente o tratamento com o antibiótico adequado, mesmo não tendo recurso suficiente para confirmação diagnóstica (Bahia, 2019). Após o início do tratamento o doente poderá ser transferido para um hospital de referência, obrigatoriamente em ambulância com acompanhamento médico (Bahia, 2019). O contato telefônico prévio da central de regulação de leitos com o hospital de referência é imprescindível para se certificar da disponibilidade de vaga, evitando assim o deslocamento desnecessário e arriscado de uma pessoa em estado potencialmente crítico. Durante essas medidas é importante manter o paciente em isolamento durante as primeiras 24 horas do tratamento (Castiñeiras, Martins, \& Fernando, 2009).

A adoção imediata do tratamento adequado não impede a coleta de material (líquor, sangue ou raspado de lesões 
petequeais) para o esclarecimento do diagnóstico etiológico através de exames laboratoriais, mas se recomenda que a coleta das amostras seja feita o mais próximo possível do início do tratamento (Bahia, 2019). A confirmação laboratorial definitiva do diagnóstico é usualmente feita através do isolamento em cultivo da N. meningitidis a partir de amostras de sangue ou de líquido cefalorraquidiano (obtido por punção lombar), o que requer um certo tempo (1 a 3 dias), e é de extrema importância para a Vigilância Epidemiológica. Contudo, a demonstração direta da presença da bactéria em amostras de líquor ou raspado de lesão cutânea através da coloração pela técnica do Gram (exame simples e rápido), o que permite aumentar o grau de certeza do diagnóstico clínico (Castiñeiras et al., 2009).

Os principais exames de rotina para o esclarecimento diagnóstico laboratorial dos casos suspeitos de meningites são:

- Cultura (líquor) e Hemocultura (sangue): padrão ouro. Pode ser realizado com diversos tipos de fluidos corporais, principalmente líquido cefalorraquidiano (LCR), sangue e raspado de lesões petequiais. Tem como objetivo o isolamento da bactéria para identificação da espécie, e posteriormente o sorogrupo, sorotipo e soro subtipo do meningococo invasivo. Deve-se enviar em temperatura ambiente e replicar após 24 horas. Caso o laboratório do município não realize este exame, é necessário semear e enviar para o LACEN (Laboratório Central de Saúde Pública) (Castiñeiras, Martins, \& Fernando, 2009).

- Exame quimiocitológico do líquor: permite a contagem e o diferencial das células; e as dosagens de glicose e proteínas do LCR. Traduz a intensidade do processo infeccioso e orienta a suspeita clínica, mas não deve ser utilizado para conclusão do diagnóstico final, pelo baixo grau de especificidade. Deve ser processado em até 2 horas (Bahia, 2019).

- Bacterioscopia (líquor): Pode ser realizada a partir do LCR e outro fluidos corpóreos normalmente estéreis e de raspagem de petéquias. A coloração do LCR pela técnica de Gram permite, ainda que com baixo grau de especificidade, caracterizar morfológica e tintorialmente as bactérias presentes - no caso do meningococo, um diplococo gram-positivo. Devem ser enviadas 2 lâminas ao Lacen, 01 corada e 01 sem corar (Bahia, 2019).

- Aglutinação pelo látex (líquor e soro): detecta o antígeno bacteriano em amostras de LCR e soro, ou outros fluidos biológicos. Partículas de látex, sensibilizadas com antissoros específicos, permitem, por técnica de aglutinação rápida (em lâmina ou placa), detectar o antígeno bacteriano nas amostras. Pode ocorrer resultado falso-positivo, em indivíduos portadores do fator reumático ou em reações cruzadas com outros agentes. Após 24 horas, congelar para enviar amostra (Bahia, 2019).

- Reação em Cadeia da Polimerase (PCR): detecta o DNA da N. meningitidis presente nas amostras clínicas (LCR, soro e sangue total). Também permite a genogrupagem dos sorogrupos de meningococo. A PCR em tempo real (qPCR) é uma modificação da técnica tradicional de PCR que identifica o DNA alvo com maior sensibilidade e especificidade e em menor tempo de reação. Após 24 horas, congelar para enviar a amostra ao Lacen (Bahia, 2019).

Segundo a $3^{\text {a }}$ edição do Guia de Vigilância em Saúde, elaborado pelo Ministério as Saúde em 2019, o fluxo do diagnóstico laboratorial deve ocorrer da seguinte forma (Brasil, 2020):

1. Laboratório Local - LL

- $\quad$ Semeia o LCR;

- Realiza os exames quimiocitológico, bacterioscópico e látex (no soro e LCR);

- Encaminhar ao Lacen: o material semeado (LCR e sangue) para isolamento e identificação bacteriana; o sono e o LCR para realização de qPCR, quando implantado no Lacen; as duas lâminas de bacterioscopia para CQ, sendo uma corada e a outra não; 
- Informa os resultados à Vigilância Epidemiológica. Quando o LL realizar a cultura, deve enviar a cepa isolada para o Lacen.

2. Laboratório de Referência Estadual - Lacen

- $\quad$ Realiza o qPCR no soro e LCR, caso a técnica esteja implantada no Lacen;

- $\quad$ Procede à semeadura do LCR e/ou aos exames que não tenham sido feitos pelo LL;

- Confirma a identificação bioquímica e sorológica das cepas bacterianas recebidas ou por ele isoladas;

- $\quad$ Realiza teste de sensibilidade - Concentração Inibitória Mínima (CIM);

- Fecha os casos com a Vigilância Epidemiológica;

- Envia ao LRR (Laboratório de Referência Regional) amostras de soro e líquor para o Controle de Qualidade Analítica;

- Encaminha ao LRN (Laboratório de Referência Nacional) as cepas de Neisseria meningitidis, Haemophilus influenzae e Streptococcus pneumoniae dos casos fechados ou de resultados, respectivamente, para Controle da Qualidade (CQ) ou para conclusão diagnóstica.

\section{Laboratório de Referência Nacional - LRN}

- $\quad$ Confirma a CIM das cepas isoladas segundo critérios do Clinical and Laboratory Standard Intitute (CLSI);

- $\quad$ Procede ao CQ das cepas identificadas e que lhe foram enviadas pelos Lacen;

- Realiza os exames necessários para os resultados inconclusivos enviados pelos Lacen e qPCR em casos especiais, como surtos.

Além disso, o perfeito acondicionamento das amostras é importante para o êxito dos procedimentos laboratoriais. Para cultura, deve-se realizar a semeadura do LCR no local de coleta sempre que possível. Caso contrário, é necessário enviá-lo em temperatura ambiente para ser semeado no laboratório. Os "kits meningites", necessários ao diagnóstico laboratorial, estão disponíveis nas Regionais de Saúde para serem fornecidos às unidades hospitalares quando solicitados. Os resultados e laudos laboratoriais deverão ser informados à Coordenação Geral de Laboratórios de Saúde Pública (CGLAB/MS) conforme o preconizado. Todo material deverá ser enviado ao Lacen, devidamente identificado e acompanhado de cópia da Ficha de Investigação do Sinan, que servirá de orientação quanto aos exames indicados (Bahia, 2019).

\subsection{Tratamento}

Diante a suspeita de meningite, deve ser instituída a antibioticoterapia empírica o mais precocemente possível, cobrindo os principais agentes etiológicos, de acordo com cada faixa etária para prevenir danos neurológicos secundários (Bahia, 2019). Nesse momento, opta-se pelo uso de dexametasona como terapia inicial protetora do sistema nervoso, 10 mg, IV para adultos e $15 \mathrm{mg} / \mathrm{kg}$, IV para crianças, associada a antibióticos. Além disso, em caso de encefalite, deve-se associar aciclovir ao 10mg/kg IV, 8/8h, até sair PCR negativo para Herpes Vírus Simples (Bahia, 2020).

A escolha do esquema de antibiótico deve ser feita com o objetivo de abranger o maior espectro provável agentes infeciosos prováveis. Desse modo, opta-se por cefalosporinas de terceira geração, como ceftriaxona ( $2 \mathrm{~g}$ IV a cada $12 \mathrm{~h})$ ou cefotaxima ( $2 \mathrm{~g}$ IV a cada $6 \mathrm{~h}$ ), e, vancomicina (30 a $60 \mathrm{mg} / \mathrm{kg}$ IV a cada 8 a $12 \mathrm{~h}$ ) direcionada a pacientes infectados em regiões endêmicas para pneumococo resistente a penicilina (Brasil, 2020). Em pacientes maiores de 50 anos ou imunocomprometidos deve ser considerado a cobertura para Listeria monocytogenes, associando-se ampicilina (2g IV a cada 4h) (Bahia, 2019). O moxifloxacino é uma alternativa a pacientes alérgicos à penicilina e às cefalosporinas. A duração recomendada para o uso dos é de 7 dias (Bahia, 2020). 
Inicialmente, além da antibioticoterapia devem ser associadas outras medidas de suporte, como dieta zero até a estabilização do quadro, repouso restrito no leito, isolamento respiratório 24 horas após o início do tratamento, hidratação com soro fisiológico $(0,9 \%)$ ou Ringer Lactato $(30 \mathrm{~mL} / \mathrm{Kg}, \mathrm{EV})$, oxigenação com cateter nasal, O2 3L/minuto se SatO2 <94\% (Bahia, 2019). Além disso, outras medidas assistenciais podem ser consideradas, como elevação da cabeceira a $30^{\circ}$ (contra aumento de pressão intracraniana), tratamento de infecções concomitantes e monitoramento constante, caso haja alteração do quadro com necessidade de intubação e/ou ressuscitação cardiopulmonar (Bahia, 2020).

Após a identificação do agente etiológico, a terapia passa a ser direcionada. Pensando em infecção por N. Meningitidis o tratamento será feito com Ceftriaxone ou Cefotaxima por um período entre 7 e 10 dias (Bahia, 2020). A evolução do quadro para uma disseminação hematogênica do meningococo leva a um quadro grave chamado de meningococcemia, que, se acompanhado por choque, a ressuscitação volumétrica, o uso precoce de inotrópico e a ventilação mecânica podem reduzir a mortalidade. Há controvérsias a respeito do uso de corticoide nessas situações (Barroso, Carvalho, Nogueira, \& Solari, 1998).

Deve-se iniciar quimioprofilaxia para todos os contactantes próximos do paciente infectado por N. meningitidis o mais precocemente possível, como moradores do mesmo domicílio e profissionais que atenderam o paciente sem a utilização dos EPIs adequados (Barroso, Carvalho, Nogueira, \& Solari, 1998). O antibiótico de escolha para a quimioprofilaxia é a rifampicina 10mg/kg/dose (máximo de 600mg) de 12/12h por 2 dias (Bahia, 2020). A rifampcina deve ser administrada simultaneamente a todos os contactantes próximos, preferencialmente até $48 \mathrm{~h}$ da exposição ao doente. Outros esquemas alternativos incluem a ceftriaxona (250mg IM dose única) e o Ciprofloxacino (500mg VO dose única) (Brasil, 2020). O Quadro 1 retrata o esquema profilático de escolha para a meningite meningocócica.

Quadro 1. Esquema profilático para a doença meningocócica.

\begin{tabular}{|c|c|c|c|c|}
\hline Droga & Idade & Dose & Intervalo & Duraçio \\
\hline \multirow{2}{*}{ Rifampicina } & $<1$ mès & $5 m g / k g / d o s e$ & $12 \mathrm{em} 12$ horas & \multirow{2}{*}{2 dias } \\
\hline & Crianças $\geq 1$ mès e adultos & $10 \mathrm{mg} / \mathrm{kg} /$ dose (máximo de $600 \mathrm{mg}$ ) & $12 \mathrm{em} 12$ horas & \\
\hline \multirow{2}{*}{ Ceftriaxona } & $<12$ anos & 125mg: intramuscular & \multirow{2}{*}{ Dose única } & \\
\hline & $\geq 12$ anos & 250mg; intramuscular & & \\
\hline Ciprofloxacino & $>18$ anos & 500mg; uso oral & Dose ûnica & \\
\hline
\end{tabular}

Fonte: Adaptado de Guia de Vigilância das Meningites, $3^{\circ}$ edição (2019).

\section{Considerações Finais}

Portanto, a partir da análise dos dados epidemiológicos, bem como das principais características fisiopatológicas apresentadas, fica clara a importância da doença meningogócica para o cenário da saúde em tempos atuais. Ao passo em que propõe uma Linha de Cuidado para tal enfermidade, esse estudo busca complementar o esquema profilático já existente para tal doença, da mesma forma em que acrescenta sugestões inéditas à área. Para que a Linha de Cuidado obtenha sucesso em sua implementação, é necessário que ela seja adotada e aplicada de forma coesa por todos os principais níveis de atenção à meningococcemia, de forma a se garantir uma rede de integração permanente à saúde pública brasileira.

Para trabalhos futuros elaborados com fundamentação teórica neste estudo, recomenda-se que as medidas de atualização a serem propostas sigam a tendência de unificação nos níveis de Atenção à Saúde relacionados à Meningococcemia, de forma que a unificação da cobertura terapêutica oferecida pelo sistema público de saúde possa se manter coesa, com as novas propostas vindo atuarem de forma complementar às medidas criadas por meio da Linha de Cuidado 
presente neste trabalho.

\section{Referências}

Apicella, M., \& Kaplan, S. L. (2020). Microbiology and pathobiology of Neisseria meningitidis. Up to Date Electronic version, 21.

Bahia. (2019). Guia de Vigilância das Meningites. https://bvsms.saude.gov.br/bvs/publicacoes/guia_vigilancia_saude_3ed.pdf.

Bahia. (2017). Protocolo para Atendimento dos Casos Suspeitos de Meningites e Meningococcemia. http://www.saude.ba.gov.br/wpcontent/uploads/2019/05/2019-Protocolo-para-Atendimento-das-Meningites-e-Meningococcemias.pdf.

Bahia. (2020). Boletim Epidemiológico das Meningites. http://www.saude.ba.gov.br/wp-content/uploads/2018/02/boletMeningitesAbr2020_n\%C2\%BA01Revisado-2.pdf.

Barroso, D. E., Carvalho, D. M. D., Nogueira, S. A., \& Solari, C. A. (1998). Doença meningocócica: epidemiologia e controle dos casos secundários. Revista de Saúde Pública, 32, 89-97.

Bennett, J. E., Dolin, R., \& Blaser, M. J. (Eds.). (2020). Mandell, Douglas y Bennett. Enfermedades infecciosas. Principios y práctica. Elsevier Health Sciences.

Branco, R. G., Amoretti, C. F., \& Tasker, R. C. (2007). Doença meningocócica e meningite. Jornal de pediatria, 83, S46-S53.

Brasil. (2020). Resolução $\mathrm{n}^{\circ}$ 2.271, de 14 de fevereiro de 2020. https://www.in.gov.br/en/web/dou/-/resolucao-n-2.271-de-14-de-fevereiro-de-2020253606068

Brasil. (2021). Banco de dados do Sistema Único de Saúde. http://tabnet.datasus.gov.br/cgi/tabcgi.exe?sinannet/cnv/meninbr.def.

Brazil. (1985). Terminologia básica em saúde (Vol. 8). Centro de Documentação do Ministério da Saúde.

Briozo, R. A., \& Musetti, M. A. (2015). Método multicritério de tomada de decisão: aplicação ao caso da localização espacial de uma Unidade de Pronto Atendimento-UPA 24 h. Gestão \& Produção, 22, 805-819.

Carvalho, M. C. R., \& de Souza Chinalia, E. L. (2016). Atenção terciária e o processo do cuidado. Sínteses: Revista Eletrônica do SimTec, (6), $201-201$.

Castiñeiras, T. M. P., Martins, L. G., \& Fernando, S. V. (2009). Doença meningocócica.

Chachá, R. C. V., \& Junior, P. L. (2003). Monoartrite e poliartrite aguda. Medicina (Ribeirao Preto), 36(2/4), 418-426.

da Silveira Bender, A., Molina, L. R., \& de Mello, A. L. S. F. (2010). Absenteísmo na atenção secundária e suas implicações na atenção básica. Espaço para Saúde, 11(2), 56-65.

Erdmann, A. L., Andrade, S. R. D., Mello, A. L. S. F. D., \& Drago, L. C. (2013). La atención secundaria en salud: mejores prácticas en la red de servicios. Revista Latino-Americana de Enfermagem, 21(SPE), 131-139.

Escobar, A. M. V., Suárez, A. C. R., \& Calfat, G. J. (2007). Meningococcemia aguda. Revista de la Asociación Colombiana de Dermatología y Cirugía Dermatológica, 15(1), 61-64.

Goldeman, L., \& Ausiello, D. (2009). Cecil medicina. In Cecil medicina.

Kuschnir, R., \& Chorny, A. H. (2010). Redes de atenção à saúde: contextualizando o debate. Ciência \& Saúde Coletiva, 15, $2307-2316$.

Malta, D. C., \& Merhy, E. E. (2010). O percurso da linha do cuidado sob a perspectiva das doenças crônicas não transmissíveis. Interface-Comunicação, Saúde, Educação, 14, 593-606.

Medeiros, F. A., de Araújo-Souza, G. C., Albuquerque-Barbosa, A. A., \& Clara-Costa, I. D. C. (2010). Acolhimento em uma Unidade Básica de Saúde: a satisfação do usuário em foco. Revista de Salud Pública, 12, 402-413.

Mendes, E. V. (2015). A construção social da atenção primária à saúde. Brasília: Conselho Nacional de Secretários de Saúde, 45.

Mendes, E. V. (2008). As redes de atenção à saúde. Rev Med Minas Gerais, 18(4 Supl 4), S3-S11.

Ministério da Saúde (BR). Secretaria de Vigilância em Saúde. (2014). Guia de vigilância em saúde.

Noronha, J. C. D., Lima, L. D. D., \& Machado, C. V. (2008). Sistema Único de Saúde-SUS. In Políticas e sistemas de saúde no Brasil (pp. 435-472).

Oliveira, N. R. D. C., Santos, H. F. D. A. C., Garcia, P. T., Pinho, J. R. O., Reis, R. S., Oliveira, A. E. F. D., ... \& França, R. M. (2015). Redes de atenção à saúde: a atenção à saúde organizada em redes.

Pacheco, L. M. D. M., Pereira, L. A. A., Silva, Z. P. D., Teixeira, M. D. C. B., \& Lopes, A. C. (2007). Doença meningocócica: aspectos epidemiológicos, fatores de risco e prevenção. Rev. Soc. Bras. Clín. Méd, 87-91.

Paim, A. C. B., Gregio, M. M., \& Garcia, S. P. (2019). Perfil epidemiológico da meningite no estado de Santa Catarina no período de 2008 a 2018. Arquivos Catarinenses de Medicina, 48(4), 111-125. 
Research, Society and Development, v. 11, n. 2, e45611226131, 2022

(CC BY 4.0) | ISSN 2525-3409 | DOI: http://dx.doi.org/10.33448/rsd-v11i2.26131

Sá, G. B. A. R. D., Dornelles, G. C., Cruz, K. G., Amorim, R. C. D. A., Andrade, S. S. C. D. A., Oliveira, T. P., ... \& Souza, M. D. F. M. D. (2016). O Programa Academia da Saúde como estratégia de promoção da saúde e modos de vida saudáveis: cenário nacional de implementação. Ciência \& Saúde Coletiva, 21, 1849-1860.

Salzman, M. B., \& Rubin, L. G. (1996). Meningococcemia. Infectious disease clinics of North America, 10(4), 709-725.

Silva, N. E. K., Sancho, L. G., \& Figueiredo, W. D. S. (2016). Entre fluxos e projetos terapêuticos: revisitando as noções de linha do cuidado em saúde e itinerários terapêuticos. Ciência \& Saúde Coletiva, 21, 843-852.

Solla, J., \& Chioro, A. (2008). 17. ATENÇÃO AMBULATORIAL ESPECIALIZADA.

Stella-Silva, N., Oliveira, S. A., \& Marzochi, K. B. F. (2007). Doença meningocócica: comparação entre formas clínicas. Revista da Sociedade Brasileira de Medicina Tropical, 40, 304-310.

Takada, S., Fujiwara, S., Inoue, T., Kataoka, Y., Hadano, Y., Matsumoto, K., ... \& Shimizu, T. (2016). Meningococcemia in adults: a review of the literature. Internal Medicine, 55(6), 567-572.

Teixeira, A. B., Cavalcante, J. C. V., Moreno, I. C., Soares, I. A., \& Holanda, F. O. A. (2018). Meningite bacteriana: uma atualização. RBAC, 50(4), 327-9.

Temporão, J. G. (2010). PORTARIA N 4.279, DE 30 DE DEZEMBRO DE 2010. Estabelece diretrizes para a organização da Rede de Atenção à Saúde no âmbito do Sistema Único de Saúde (SUS). Brasília: Ministério da Saúde. Diário Oficial da União.

Vendruscolo, C., Ferraz, F., Tesser, C. D., \& Trindade, L. D. L. (2019). Núcleo ampliado de saúde da família: espaço de interseção entre atenção primária e secundária. Texto \& Contexto-Enfermagem, 28. 